\title{
BMJ Open Out-of-hours and weekend admissions to Danish medical departments: admission rates and 30-day mortality for 20 common medical conditions
}

\author{
Betina Vest-Hansen, Anders Hammerich Riis, Henrik Toft Sørensen, \\ Christian Fynbo Christiansen
}

To cite: Vest-Hansen B, Riis AH, Sørensen HT, et al. Out-of-hours and weekend admissions to Danish medical departments: admission rates and 30-day mortality for 20 common medical conditions. BMJ Open 2015;5:e006731. doi:10.1136/bmjopen-2014006731

- Prepublication history and additional material is available. To view please visit the journal (http://dx.doi.org/ 10.1136/bmjopen-2014006731).

Received 24 September 2014 Revised 26 January 2015 Accepted 6 February 2015

CrossMark

Department of Clinical Epidemiology, Aarhus University Hospital, Aarhus N, Denmark

Correspondence to Dr Betina Vest-Hansen; bvh@clin.au.dk

\section{ABSTRACT}

Objectives: Knowledge on timing of admissions and mortality for acute medical patients is limited. The aim of the study was to examine hospital admission rates and mortality rates for patients with common medical conditions according to time of admission.

Design: Nationwide population-based cohort study. Setting: Population of Denmark.

Participants: Using the Danish National Registry of Patients covering all Danish hospitals, we identified all adults with the first acute admission to a medical department in Denmark during 2010.

\section{Primary and secondary outcome measures:}

Hourly admission rates and age-standardised and sex-standardised 30-day mortality rates comparing weekday office hours, weekday out of hours, weekend daytime hours and weekend night-time hours.

Results: In total, 174192 acute medical patients were included in the study. The admission rates (patients per hour) were 38.7 (95\% Cl 38.4 to 38.9 ) during weekday office hours, $13.3(95 \% \mathrm{Cl} 13.2$ to 13.5) during weekday out of hours, $19.8(95 \% \mathrm{Cl}$ 19.6 to 20.1) during weekend daytime hours and 7.9 ( $95 \% \mathrm{Cl} 7.8$ to 8.0 ) during weekend night-time hours. Admission rates varied between medical conditions. The proportion of patients admitted to an intensive care unit (ICU) increased outside of office hours. The age-standardised and sex-standardised 30-day mortality rate was $5.1 \%(95 \% \mathrm{Cl} 5.0 \%$ to $5.3 \%)$ after admission during weekday office hours, $5.7 \%$ (95\% CI $5.5 \%$ to $6.0 \%$ ) after admission during weekday out of hours, $6.4 \%(95 \% \mathrm{Cl} 6.1 \%$ to $6.7 \%)$ after admission during weekend daytime hours and $6.3 \%$ $(95 \% \mathrm{Cl} 5.9 \%$ to $6.8 \%)$ after admission during weekend night-time hours. For the majority of the medical conditions examined, weekend admission was associated with highest mortality.

Conclusions: While admission rates decreased from office hours to weekend hours there was an observed increase in mortality. This may reflect differences in severity of illness as the proportion admitted to an ICU increased during the weekend.

\section{Strengths and limitations of this study}

- This study is the first to analyse hourly admission rates and mortality rates associated with time of admission in 20 common conditions among acute medical patients in a populationbased design

- We provide a subtle categorisation of time of admission including weekday office hours, weekday out of hours, weekend daytime hours and weekend night-time hours.

- Our study lacked clinical data on severity of disease and staffing level, but included information on the proportion admitted to intensive care units and the proportion receiving specific intensive care treatment according to time of admission.

\section{INTRODUCTION}

Acute hospital admission rates decrease during weekends, but an admission during the weekend has been associated with higher in-hospital mortality, an association termed 'the weekend effect'. ${ }^{1-16}$ The weekend effect has been observed among acutely hospitalised patients in differing healthcare systems, including those in Canada, the USA and Australia, as well as in European countries. Understanding the higher short-term mortality associated with weekend admissions is important for clinicians and for healthcare planners. Two possible explanations for the weekend effect are the changes in the availability of specialised care or changes in patient characteristics, for example, disease severity. ${ }^{17}$

A more subtle categorisation of time of admission in patients admitted during weekday office hours and out of hours, as well as daytime hours and night-time hours during the weekend, may clarify important differences in patient characteristics. Furthermore, admission rates for common medical conditions in these 
time periods may serve as a proxy of the changes in referral threshold and together with mortality rates add to the understanding of the weekend effect. Variation in timing of admission and mortality rates for common medical conditions has, to the best of our knowledge, not previously been examined. Previous studies examining 'out of hours' and mortality have primarily investigated 'out of hours' as the time outside regular hours/office hours, not distinguishing between 'Office' and 'Out of hours' timings during weekdays, nor between daytime and night-time hours of the weekend. ${ }^{8}$

We therefore examined the hourly admission rates and 30-day mortality rates for patients with 20 common medical conditions comparing weekday office hours, weekday out of hours, weekend daytime hours and weekend night-time hours in a cohort of acute medical patients with their first admission to departments of medicine during 2010 in Denmark.

\section{METHODS}

\section{Study design and setting}

In this register-based historic cohort study using prospectively collected data, we identified all acute hospital admissions to medical departments in Denmark between 1 January and 31 December 2010, as recorded in the Danish National Registry of Patients (DNRP). The DNRP is a central medical registry covering public as well as private hospitals that record information on all hospital admissions to non-psychiatric hospitals since 1977, and all visits to emergency departments and hospital specialist clinics since 1995 . The record of each admission or visit is linked to the unique Civil Personal Registration (CPR) number. In the study period, the DNRP was managed by the National Board of Health, but it is currently managed by Statens Serum Institut (SSI). After necessary approvals, data from the DNRP can be accessed by researchers in Denmark by application to SSI. In Denmark, private hospitals account for less than $1 \%$ of the total number of beds and they do not provide acute care. ${ }^{18}$

General practitioners (GPs) have a key role in referring patients to the hospital departments since virtually every Danish resident is affiliated with a personal GP. Outside regular office hours, GPs serve the patients from central regional clinics by providing phone service and consultation. Acute hospital admission is also available through a 1-1-2 emergency call, which provides ambulance service to the patient. ${ }^{19}$ Finally, patients can present themselves to an emergency department on a $24 \mathrm{~h}$ basis. ${ }^{20}$ In the study period, some emergency departments implemented a mandatory preadmission assessment based on a telephone call before arrival. Denmark has a free, tax-funded healthcare system, which assures that all residents (5534738 million persons as of 1 January 2010) in rural and in urban areas have unrestricted and equal access to GPs and to specialist care in hospitals. ${ }^{21} 22$

\section{Study population}

The cohort, which included all patients with their first acute admission to medical departments in Denmark between 1 January and 31 December 2010, has previously been described. ${ }^{23}$ For this present study, we excluded patients with an inpatient stay within the preceding 30 days or earlier on the day of admission.

\section{Time of admission}

Time of admission was defined as weekday office hours, weekday out of hours, weekend daytime hours, and weekend night-time hours. Public holidays, for example, Easter and Christmas, were considered weekend days. Weekday office hours were from Monday to Friday from 8:00 to 16:59. Weekday out of hours were from Monday to Friday from 17:00 to 7:59, except Friday night from 22:00 to 23:59 and Monday morning from 00:00 to 7:59, which were considered part of the weekend. Weekend daytime hours were Saturday and Sunday from 9:00 to 21:59. Weekend night-time hours were Saturday and Sunday from 22:00 to 23:59 and from 00:00 to 8:59 plus Friday night from 22:00 to 23:59, and Monday from 00:00 to 7:59. Admission rates were computed hourly according to time of admission. An overall estimate of the admission rate per 100000 citizen ( $\geq 15$ years) was computed.

\section{Mortality}

Each Danish resident is assigned a unique personal identification number (CPR number), at birth or on immigration, by the Danish Civil Registration System (CRS). ${ }^{24}$ Information on all-cause mortality within 30 days following the index date was captured by linking patients' CPR number to the CRS. The CRS was established in 1968 to collect and maintain information on vital status, marital status, residency and migration for all residents of Denmark. The CRS thus contains complete up-to-date data on the vital status of all patients in our study. Patients were followed from their index date until death from any cause, emigration, or 30 days after the index date, whichever came first.

\section{Patient characteristics}

The DNRP provided the unique code for each hospital and department, admission type (ie, acute), date of admission (index date), hour and minute of admission (00:00-23:59), source of admission (hospital specialist clinic, emergency department or direct referral), procedure codes for an intensive care unit (ICU) admission and specific intensive care treatment, date of discharge and discharge diagnoses, with one primary diagnosis reflecting the reason for admission and up to 19 secondary diagnoses indicating additional chronic or acute diseases. Diagnoses were coded according to the International Classification of Diseases, Revision 10 (ICD-10).

By tabulation of the primary ICD-10 diagnoses assigned after the index admission, considered to be the main reason for admission, we identified 20 common 
conditions among acute medical patients, that is, pneumonia, erysipelas, bacteraemia/sepsis, urinary tract infection, anaemia, diabetes, dehydration, alcohol intoxication, transient ischaemic attack, angina, acute myocardial infarction, atrial fibrillation, heart failure, hypertension, stroke, chronic obstructive pulmonary disorder, respiratory failure, gastroenteritis, syncope and suspected acute myocardial infarction (ICD-10 codes provided in online supplementary appendix table $\mathrm{S} 1$ ).

To capture clinically important morbidity, data on the 19 conditions included in the Charlson Comorbidity Index (CCI) were obtained from the DNRP for the 5 years preceding the index date (ICD-10 codes provided in online supplementary appendix table S2). The CCI score was divided into low (score of 0 ), moderate (score of 1-2) and high (score of 3 or higher). From the CRS, data on marital status (married, never married, divorced, widowed and unknown) were provided. We computed length of hospital stay as time from the index date to final hospital discharge, including in-hospital and interhospital transfers.

\section{Statistical analysis}

We classified patients as admitted during weekday office hours, weekday out of hours, weekend daytime hours, and weekend night-time hours, and characterised them according to patient characteristics. The hourly admission rates and the 30-day mortality rates were computed for the common medical conditions according to time of admission. To compute comparable 30-day mortality rates for different times of admission, we used direct standardisation. ${ }^{25}$ We applied the observed age-specific and sex-specific mortality rates to a standard population defined as the patients admitted during weekday office hours. That is, for each time period, we estimated what would have been the 30-day mortality rate in our standard population if the agespecific and sex-specific mortality rates equalled those of the time period of interest. In a sensitivity analysis, we included the CCI score in the standardisation. We also reported the proportions of patients admitted to an ICU within three days following the index date and during the entire hospital stay. Additionally, we reported the proportions of patients receiving specific intensive care treatment. An ICU admission serves as a proxy for the severity of the disease and of the availability of an ICU bed.

In a subgroup analysis, the admission rate, 30-day mortality rate and ICU admissions during the four time periods were analysed only among patients admitted through the emergency department. To acknowledge the effect from public holidays on our estimates, we analysed the mortality rates associated with public holidays compared with all other days, including weekdays and weekend. We used direct standardisation to the age and gender distribution of the study population admitted outside public holidays. Data were analysed with the statistical software package STATA (V.11, Stata Corp, College Station, Texas, USA).

\section{RESULTS}

\section{Patient characteristics}

A total of 264265 patients with an acute first-time admission to medical departments in Denmark during 2010 were registered. After excluding patients without residency in Denmark $(n=505)$ and patients with a hospital admission within the preceding 30 days or on the day of the index admission ( $\mathrm{n}=89568), 174192$ patients were included in the study. Of these patients, $50.4 \%$ ( $\mathrm{n}=87$ 764) were admitted during weekday office hours, $24.9 \%(\mathrm{n}=43312)$ during weekday out of hours, $16.7 \%$ $(\mathrm{n}=29$ 140) during weekend daytime hours and 8\% $(\mathrm{n}=13$ 976) during weekend night-time hours. As shown in table 1, patients admitted during weekday office hours tended to be older and had slightly higher CCI scores than patients admitted during other time periods. Weekend night-time hours were the only time of admission when males constituted the highest proportion of patients $(50.8 \%)$. No major differences among patients were observed with regard to the individual CCI conditions. During weekday office hours, $15.1 \%$ were admitted through the emergency department, while 33.5\% were admitted through the emergency department during weekday out of hours. Similarly, weekend daytime and weekend night-time hours were associated with a high rate of admissions through the emergency department (30.2\% and 33\%, respectively).

Weekend night-time hours were associated with the highest proportion of patients admitted to an ICU within the first three days (4.4\%) compared with weekend daytime hours $(3.2 \%)$, weekday out of hours $(3.1 \%)$ and weekday office hours $(2 \%$; online supplementary appendix table S3). For more than half of the individual medical conditions we examined, the highest risk of an ICU admission within 3 days after the index date was associated with an admission during weekend night-time hours (online supplementary appendix table S3). For all 20 medical conditions except respiratory failure, admission weekday office hours were associated with the lowest risk of an ICU admission. In addition, we found that the proportion of patients receiving specific intensive care treatments, including mechanical ventilation, renal replacement therapy and use of inotropes/vasopressors, was highest for the patients who were admitted during weekend night-time hours. The proportion of patients who received multiple therapies was highest among the patients admitted outside office hours (table 2).

\section{Admission rates}

The admission rate during weekday office hours was 38.7 (95\% CI 38.4 to 38.9 ) patients per hour, and corresponding figures were 13.3 (95\% CI 13.2 to 13.5) during weekday out of hours, 19.8 (95\% CI 19.6 to 20.1) during 
Table 1 Demographic and clinical characteristics of 174192 patients with an acute admission to a department of medicine, by time of admission, Denmark, 2010

\begin{tabular}{|c|c|c|c|c|}
\hline & \multicolumn{2}{|l|}{ Weekday } & \multicolumn{2}{|l|}{ Weekend } \\
\hline & $\begin{array}{l}\text { Office hours } \\
\text { (8:00-16:59) }\end{array}$ & $\begin{array}{l}\text { Out of hours } \\
(17: 00-7: 59)\end{array}$ & $\begin{array}{l}\text { Day } \\
(9: 00-21: 59)\end{array}$ & $\begin{array}{l}\text { Night (22:00-8:59) plus } \\
\text { Friday 22:00-23:59 and } \\
\text { Monday 00:00-7:59 }\end{array}$ \\
\hline Overall & 87764 (50.4\%) & $43312(24.9 \%)$ & $29140(16.7 \%)$ & $13976(8.0 \%)$ \\
\hline \multicolumn{5}{|l|}{ Age groups } \\
\hline $15-39$ & $9291(10.6)$ & $7246(16.7)$ & 3960 (13.6) & $2528(18.1)$ \\
\hline $40-59$ & $19888(22.7)$ & $10902(25.2)$ & 6764 (23.2) & $3456(24.7)$ \\
\hline $60-79$ & $36722(41.8)$ & $15794(36.5)$ & $11079(38.0)$ & $5146(36.8)$ \\
\hline $80+$ & $21863(24.9)$ & $9370(21.6)$ & $7337(25.2)$ & $2846(20.4)$ \\
\hline Age, median (years (IQR)) & $68(54-79)$ & $64(47-78)$ & $67(51-80)$ & $64(46-77)$ \\
\hline \multicolumn{5}{|l|}{ Gender } \\
\hline Female & 45877 (52.3) & 22175 (51.2) & $15073(51.7)$ & $6880(49.2)$ \\
\hline Male & 41887 (47.7) & $211375(48.8)$ & 14067 (48.3) & $7096(50.8)$ \\
\hline \multicolumn{5}{|l|}{ Charlson Comorbidity Index score } \\
\hline 0 & $49384(56.3)$ & $25710(59.4)$ & $16647(57.1)$ & $8055(57.6)$ \\
\hline $1-2$ & $27302(31.1)$ & $12687(29.3)$ & 8996 (30.9) & $4267(30.5)$ \\
\hline $3+$ & $11078(12.6)$ & 4915 (11.4) & $3497(12.0)$ & $1654(11.8)$ \\
\hline \multicolumn{5}{|c|}{ Presence of diseases included in the Charlson Comorbidity Index } \\
\hline Myocardial infarction & $3246(3.7)$ & $1658(3.8)$ & $1117(3.8)$ & $590(4.2)$ \\
\hline Congestive heart failure & $5735(6.5)$ & $2477(5.7)$ & $1748(6.0)$ & $913(6.5)$ \\
\hline Peripheral vascular disease & $4683(5.3)$ & $1926(4.4)$ & $1388(4.8)$ & $686(4.9)$ \\
\hline Cerebrovascular disease & $8110(9.2)$ & 4052 (9.3) & $2917(10.0)$ & $1353(9.8)$ \\
\hline Dementia & $1920(2.2)$ & $1013(2.3)$ & $769(2.6)$ & $296(2.1)$ \\
\hline Chronic pulmonary disease & $9934(11.3)$ & $4758(11.0)$ & $3296(11.3)$ & $1691(12.1)$ \\
\hline Connective tissue disease & $2977(3.4)$ & $1181(2.7)$ & $889(3.1)$ & $386(2.8)$ \\
\hline Ulcer disease & $2479(2.8)$ & $1138(2.6)$ & $778(2.7)$ & 367 (2.6) \\
\hline Mild liver disease & $1435(1.6)$ & $691(1.6)$ & 451 (1.6) & 209 (1.5) \\
\hline Diabetes without end-organ damage & $7154(8.2)$ & $3362(7.8)$ & $2268(7.8)$ & $1099(7.9)$ \\
\hline Diabetes with end-organ damage & $4337(4.9)$ & $2101(4.9)$ & $1386(4.8)$ & $675(4.8)$ \\
\hline Hemiplegia & $313(0.4)$ & $163(0.4)$ & $106(0.4)$ & $53(0.4)$ \\
\hline Moderate to severe renal disease & $3036(3.5)$ & $1289(3.0)$ & $918(3.2)$ & $432(3.1)$ \\
\hline Non-metastatic solid tumour & $7555(8.6)$ & $3157(7.3)$ & $2393(8.2)$ & $1032(7.4)$ \\
\hline Leukaemia & $500(0.6)$ & $193(0.5)$ & $131(0.5)$ & $56(0.4)$ \\
\hline Lymphoma & $874(1.0)$ & $354(0.8)$ & $270(0.9)$ & $107(0.8)$ \\
\hline Moderate to severe liver disease & $511(0.6)$ & $202(0.5)$ & $159(0.6)$ & $85(0.6)$ \\
\hline Metastatic cancer & $1035(1.2)$ & $373(0.9)$ & $360(1.2)$ & $140(1.0)$ \\
\hline AIDS & $152(0.2)$ & $85(0.2)$ & $50(0.2)$ & $23(0.2)$ \\
\hline \multicolumn{5}{|l|}{ Marital status } \\
\hline Married & $40881(46.6)$ & $18719(43.2)$ & 12794 (43.9) & $6358(45.5)$ \\
\hline Never married & $14140(16.1)$ & 9206 (21.3) & $5364(18.4)$ & 2981 (21.3) \\
\hline Divorced & $12414(14.1)$ & $6486(15.0)$ & $4230(14.5)$ & 2064 (14.8) \\
\hline Widowed & 20325 (23.2) & $8904(20.6)$ & $6751(23.2)$ & $2573(18.4)$ \\
\hline Unknown & 4 & 0 & 1 & 0 \\
\hline \multicolumn{5}{|l|}{ Admission source } \\
\hline Hospital outpatient specialist clinic & $5781(6.6)$ & $2251(5.2)$ & 1139 (3.9) & 541 (3.9) \\
\hline Emergency department & $13225(15.1)$ & $14492(33.5)$ & $8810(30.2)$ & $4618(33.0)$ \\
\hline Other & 69438 (79.0) & $27343(63.1)$ & $19610(67.3)$ & 8997 (64.4) \\
\hline Length of hospital stay (median (days)) & $3(1-7)$ & $2(1-7)$ & $3(1-7)$ & $3(1-6)$ \\
\hline \multicolumn{5}{|l|}{ Common medical conditions } \\
\hline Pneumonia & $5886(6.7)$ & $2797(6.5)$ & $2197(7.5)$ & $978(7.0)$ \\
\hline Erysipelas & $991(1.1)$ & $513(1.2)$ & 367 (1.3) & $125(0.9)$ \\
\hline Bacteraemia/sepsis & $1201(1.4)$ & $759(1.8)$ & $563(1.9)$ & $238(1.7)$ \\
\hline Urinary tract infection & $1944(2.2)$ & $996(2.3)$ & $740(2.5)$ & $300(2.2)$ \\
\hline Anaemia & $2384(2.7)$ & $417(1.0)$ & $266(0.9)$ & $93(0.7)$ \\
\hline Diabetes & $1540(1.8)$ & $507(1.2)$ & $326(1.1)$ & $158(1.1)$ \\
\hline Dehydration & $2073(2.4)$ & $953(2.2)$ & $697(2.4)$ & $213(1.5)$ \\
\hline Alcohol intoxication & 989 (1.1) & 994 (2.3) & $556(1.9)$ & $388(2.8)$ \\
\hline
\end{tabular}


Table 1 Continued

\begin{tabular}{|c|c|c|c|c|}
\hline & \multicolumn{2}{|l|}{ Weekday } & \multicolumn{2}{|l|}{ Weekend } \\
\hline & $\begin{array}{l}\text { Office hours } \\
(8: 00-16: 59)\end{array}$ & $\begin{array}{l}\text { Out of hours } \\
(17: 00-7: 59)\end{array}$ & $\begin{array}{l}\text { Day } \\
(9: 00-21: 59)\end{array}$ & $\begin{array}{l}\text { Night (22:00-8:59) plus } \\
\text { Friday 22:00-23:59 and } \\
\text { Monday 00:00-7:59 }\end{array}$ \\
\hline Transient ischaemic attack & $1380(1.6)$ & $811(1.9)$ & $609(2.1)$ & $200(1.4)$ \\
\hline Angina & $2191(2.5)$ & $1000(2.3)$ & $616(2.1)$ & $408(2.9)$ \\
\hline Acute myocardial infarction & $2274(2.6)$ & $1317(3.0)$ & $997(3.4)$ & $694(5.0)$ \\
\hline Atrial fibrillation & $3707(4.2)$ & $1170(2.7)$ & $889(3.1)$ & $354(2.5)$ \\
\hline Heart failure & $1645(1.9)$ & $535(1.2)$ & $300(1.0)$ & $207(1.5)$ \\
\hline Hypertension & $1173(1.3)$ & $487(1.1)$ & $329(1.1)$ & $136(1.0)$ \\
\hline Stroke & 3187 (3.6) & $1587(3.7)$ & $1407(4.8)$ & $515(3.7)$ \\
\hline Chronic obstructive pulmonary disorder & 2869 (3.3) & $1273(2.9)$ & $926(3.2)$ & $545(3.9)$ \\
\hline Respiratory failure & $1120(1.3)$ & 559 (1.3) & $414(1.4)$ & $224(1.6)$ \\
\hline Gastroenteritis & 1179 (1.3) & $612(1.4)$ & $466(1.6)$ & $231(1.7)$ \\
\hline Syncope & $1554(1.8)$ & $1195(2.8)$ & $865(3.0)$ & $336(2.4)$ \\
\hline Suspected acute myocardial infarction & $3719(4.2)$ & $2304(5.3)$ & $1455(5.0)$ & $712(5.1)$ \\
\hline Other & $44758(51.0)$ & $22526(52.0)$ & $14155(44.6)$ & $6921(49.5)$ \\
\hline
\end{tabular}

weekend daytime hours and 7.9 (95\% CI 7.8 to 8.0) during weekend night-time hours (table 3). The hourly admission rates per 100000 citizens ( $\geq 15$ years) in the four time periods were 0.91 (95\% CI 0.87 to 0.95$), 0.31$ (95\% CI 0.29 to 0.33$), 0.47$ (95\% CI 0.43 to 0.50$)$ and 0.19 (95\% CI 0.17 to 0.21 ), respectively. Among the common medical conditions, pneumonia had the overall highest admission rate in all time periods. Anaemia, diabetes, atrial fibrillation and heart failure had the relatively largest decreases in admission rates from weekday office hours to the other time periods, while a condition such as alcohol intoxication was associated with a more stable admission rate across time periods. The medical conditions with the lowest admission rates during weekend night-time hours were anaemia, erysipelas, diabetes and hypertension.

\section{Mortality}

Table 4 portrays the crude and age-standardised and sexstandardised 30-day mortality rate for the common medical conditions. The age-standardised and sexstandardised 30-day mortality rate was $5.1 \% \quad(95 \%$ CI $5.0 \%$ to $5.3 \%$ ) for patients admitted during weekday office hours, $5.7 \%$ (95\% CI $5.5 \%$ to $6.0 \%$ ) for patients admitted during weekday out of hours, $6.4 \%$ (95\% CI $6.1 \%$ to $6.7 \%$ ) for patients admitted during weekend daytime hours and $6.3 \%(95 \%$ CI $5.9 \%$ to $6.8 \%)$ for patients admitted during weekend night-time hours. The medical conditions with the highest mortality rate in all four time periods were respiratory failure and bacteraemia/sepsis. In 17 of the 20 common medical conditions examined in this study, the highest mortality rate was associated with an admission during weekend, of which 7 medical conditions had the highest mortality rate associated with weekend night-time hours admission: erysipelas, bacteraemia/sepsis, anaemia, angina, atrial fibrillation, chronic obstructive pulmonary disorder and syncope. Urinary tract infection was the only condition associated with the highest mortality rate for admissions during weekday office hours (table 4). For

Table 2 ICU admissions and procedures

\begin{tabular}{|c|c|c|c|c|}
\hline & \multicolumn{2}{|l|}{ Weekday } & \multicolumn{2}{|l|}{ Weekend } \\
\hline & $\begin{array}{l}\text { Office hours } \\
\text { (8:00-16:59) } \\
\text { n (\%) }\end{array}$ & $\begin{array}{l}\text { Out of hours } \\
(17: 00-7: 59) \\
n(\%)\end{array}$ & $\begin{array}{l}\text { Day } \\
(9: 00-21: 59) \\
\text { n (\%) }\end{array}$ & $\begin{array}{l}\text { Night (22:00-8:59) plus } \\
\text { Friday 22:00-23:59 and } \\
\text { Monday 00:00-7:59 } \\
\text { n (\%) }\end{array}$ \\
\hline Total & $87764(100)$ & $43312(100)$ & $29140(100)$ & $13976(100)$ \\
\hline ICU admissions & $2603(3.0)$ & $1712(4.0)$ & $1190(4.1)$ & $746(5.3)$ \\
\hline \multicolumn{5}{|l|}{ ICU procedures } \\
\hline Mechanical ventilation & $1268(1.4)$ & $795(1.8)$ & $551(1.9)$ & $321(2.3)$ \\
\hline Non-invasive mechanical ventilation & $634(0.7)$ & $369(0.9)$ & $259(0.9)$ & $159(1.1)$ \\
\hline Inotropes/vasopressor & $1024(1.2)$ & $624(1.4)$ & $443(1.5)$ & 260 (1.9) \\
\hline Renal replacement therapy & $229(0.3)$ & $136(0.3)$ & $94(0.3)$ & $53(0.4)$ \\
\hline Intensive care but no procedures & $813(0.9)$ & $597(1.4)$ & $414(1.4)$ & $279(2.0)$ \\
\hline
\end{tabular}


Table 3 Hourly admission rates for 20 common medical conditions by time of admission

\begin{tabular}{|c|c|c|c|c|}
\hline & \multicolumn{2}{|l|}{ Weekday } & \multicolumn{2}{|l|}{ Weekend } \\
\hline & $\begin{array}{l}\text { Office hours } \\
(8: 00-16: 59)\end{array}$ & $\begin{array}{l}\text { Out of hours } \\
(17: 00-7: 59)\end{array}$ & $\begin{array}{l}\text { Day } \\
(9: 00-21: 59)\end{array}$ & $\begin{array}{l}\text { Night (22:00-8:59) plus } \\
\text { Friday 22:00-23:59 and } \\
\text { Monday 00:00-7:59 }\end{array}$ \\
\hline Overall & 38.7 (38.4-38.9) & $13.3(13.2-13.5)$ & $19.8(19.6-20.1)$ & $7.9(7.8-8.0)$ \\
\hline \multicolumn{5}{|l|}{$\begin{array}{l}\text { Common medical conditions } \\
\text { Infectious diseases }\end{array}$} \\
\hline Pneumonia & $2.60(2.53-2.66)$ & $0.86(0.83-0.89)$ & $1.50(1.43-1.56)$ & $0.55(0.52-0.59)$ \\
\hline Erysipelas & $0.44(0.41-0.47)$ & $0.16(0.14-0.17)$ & $0.25(0.22-0.28)$ & $0.07(0.06-0.08)$ \\
\hline Bacteraemia/septicaemia & $0.53(0.50-0.56)$ & $0.23(0.22-0.25)$ & $0.38(0.35-0.42)$ & $0.13(0.12-0.15)$ \\
\hline Urinary tract infection & $0.86(0.82-0.90)$ & $0.31(0.29-0.33)$ & $0.50(0.47-0.54)$ & $0.17(0.15-0.19)$ \\
\hline \multicolumn{5}{|l|}{ Haematological diseases } \\
\hline Anaemia & $1.05(1.01-1.09)$ & $0.13(0.12-0.14)$ & $0.18(0.16-0.20)$ & $0.05(0.04-0.06)$ \\
\hline \multicolumn{5}{|l|}{ Endocrine and nutritional disease } \\
\hline Diabetes & $0.68(0.65-0.71)$ & $0.16(0.14-0.17)$ & $0.22(0.20-0.25)$ & $0.09(0.08-0.10)$ \\
\hline Dehydration & $0.91(0.88-0.95)$ & $0.29(0.27-0.31)$ & $0.47(0.44-0.51)$ & $0.12(0.10-0.14)$ \\
\hline \multicolumn{5}{|l|}{ Mental and behavioural disorders } \\
\hline Alcohol intoxication & $0.44(0.41-0.46)$ & $0.31(0.29-0.33)$ & $0.38(0.35-0.41)$ & $0.22(0.20-0.24)$ \\
\hline \multicolumn{5}{|l|}{ Diseases of the nervous system } \\
\hline Transient ischaemic attack & $0.61(0.58-0.64)$ & $0.25(0.23-0.27)$ & $0.41(0.38-0.45)$ & $0.11(0.10-0.13)$ \\
\hline \multicolumn{5}{|l|}{ Diseases of the circulatory system } \\
\hline Angina & $0.97(0.93-1.01)$ & $0.31(0.29-0.33)$ & $0.42(0.39-0.45)$ & $0.23(0.21-0.25)$ \\
\hline Acute myocardial infarction & $1.00(0.96-1.04)$ & $0.41(0.38-0.43)$ & $0.68(0.64-0.72)$ & $0.39(0.36-0.42)$ \\
\hline Atrial fibrillation & $1.63(1.58-1.69)$ & $0.36(0.34-0.38)$ & $0.61(0.57-0.65)$ & $0.20(0.18-0.22)$ \\
\hline Heart failure & $0.73(0.69-0.76)$ & $0.16(0.15-0.18)$ & $0.20(0.18-0.23)$ & $0.12(0.10-0.13)$ \\
\hline Hypertension & $0.52(0.49-0.55)$ & $0.15(0.14-0.16)$ & $0.22(0.20-0.25)$ & $0.08(0.06-0.09)$ \\
\hline Stroke & $1.41(1.36-1.45)$ & $0.49(0.46-0.51)$ & $0.96(0.91-1.01)$ & $0.29(0.27-0.32)$ \\
\hline \multicolumn{5}{|l|}{ Diseases of the respiratory system } \\
\hline Chronic obstructive pulmonary disorder & $1.26(1.22-1.31)$ & $0.39(0.37-0.41)$ & $0.63(0.59-0.67)$ & $0.31(0.28-0.33)$ \\
\hline Respiratory failure & $0.49(0.46-0.52)$ & $0.17(0.16-0.19)$ & $0.28(0.26-0.31)$ & $0.13(0.11-0.14)$ \\
\hline \multicolumn{5}{|l|}{ Diseases of the digestive system } \\
\hline Gastroenteritis & $0.52(0.49-0.55)$ & $0.19(0.17-0.20)$ & $0.32(0.29-0.35)$ & $0.13(0.11-0.15)$ \\
\hline \multicolumn{5}{|l|}{ Symptoms and abnormal findings } \\
\hline Syncope & $0.69(0.65-0.72)$ & $0.37(0.35-0.39)$ & $0.59(0.55-63)$ & $0.19(0.17-0.21)$ \\
\hline \multicolumn{5}{|l|}{ Factors influencing health status } \\
\hline Suspected acute myocardial infarction & $1.64(1.59-1.69)$ & $0.71(0.68-0.74)$ & $0.99(0.94-1.04)$ & $0.40(0.37-0.43)$ \\
\hline Other & $19.7(19.6-19.9)$ & $6.93(6.84-7.02)$ & $9.64(9.48-9.80)$ & $3.90(3.81-4.00)$ \\
\hline
\end{tabular}

patients admitted with hypertension or stroke, the highest mortality rate was associated with an admission during weekday out of hours. Notably, for patients with stroke, there was a substantial increase in mortality rate associated with admission during weekday out of hours compared with weekday office hours (risk difference $4.1 \%(95 \%$ CI $2.2 \%$ to $6.1 \%))$. For patients with anaemia, there was more than a doubling in mortality for patients admitted during weekend night-time hours compared with weekday office hours.

In the sensitivity analysis, which included age, sex and the CCI score in the standardisation of the 30-day mortality rates, similar results were found for the estimates in the overall cohort, as well as in the subgroups of common conditions. In our analysis of the subgroup of patients admitted through the emergency department, we identified no major differences in mortality rate or ICU admissions by time of admission (online supplementary appendix table $\mathrm{S} 4$ ). The admission rates varied with the lowest admission rate during weekend nighttime hours. The 30-day mortality rate for the medical patients who required acute admission during public holidays was $5.8 \%$ (95\% CI $5.2 \%$ to $6.3 \%$ ) compared with $5.3 \%$ (95\% CI $5.2 \%$ to $5.4 \%$ ) among the medical patients who required acute admission outside public holidays (weekend and weekdays).

\section{DISCUSSION}

Key findings

In this register-based cohort study, timing of first-time admissions varied and weekend admissions were associated with the highest proportion admitted to an ICU and the highest mortality for the majority of the conditions examined. By including weekday out of hours as a separate time of admission, we were able to discern important differences in patient characteristics, for example, the proportion of patients arriving through 


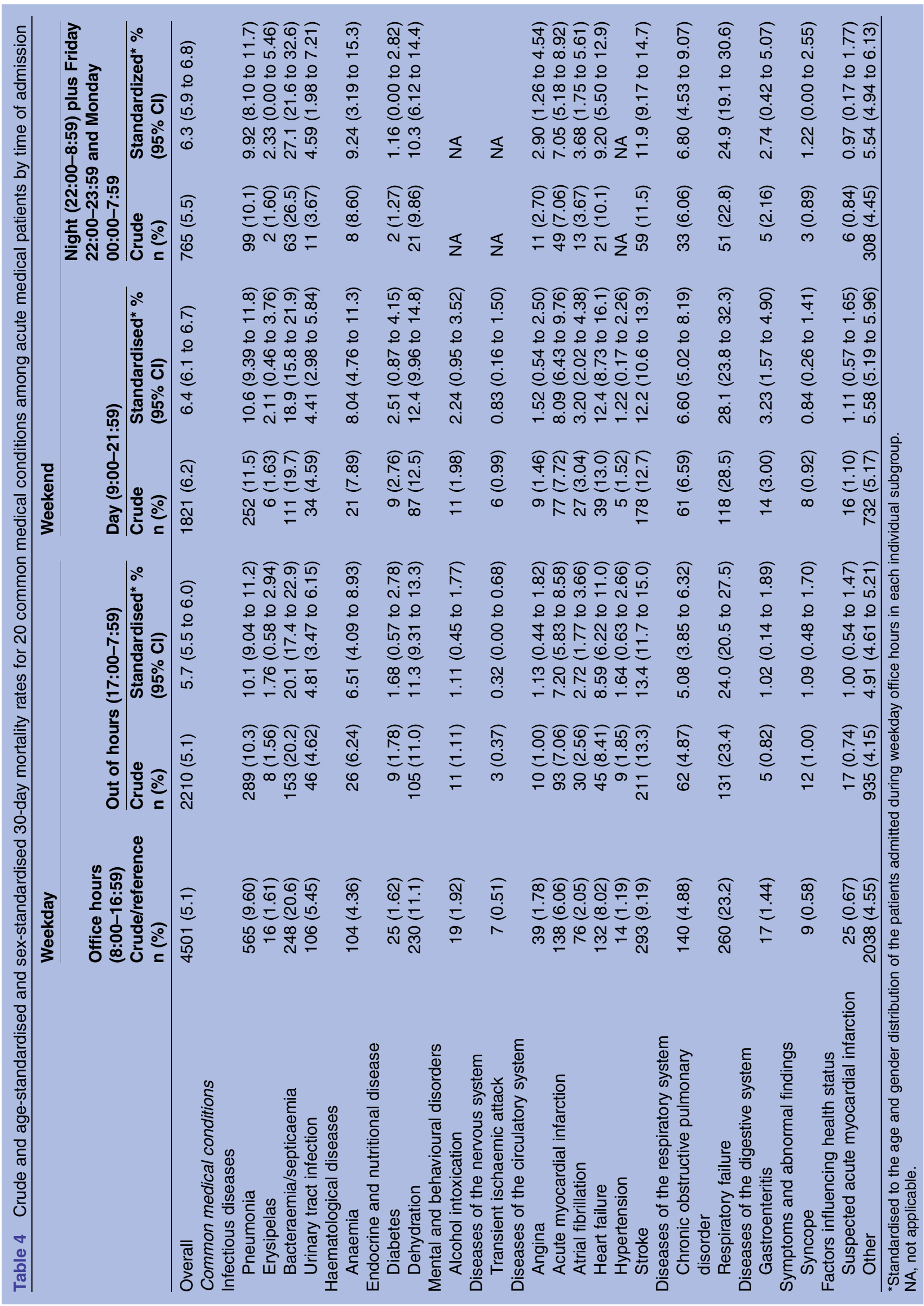


the emergency department changed dramatically from weekday office hours to weekday out of hours.

\section{Strengths and limitations}

The key strength of this cohort study was the use of a nationwide population-based medical registry that included all first-time acute admissions to departments of medicine in Denmark. The population-based design essentially removes concerns about patient selection bias, and the CPR number assigned to all Danish residents permits unambiguous individual-level linkage among all Danish administrative and medical registries.

One concern is the accuracy of data on time of admission. While the administrative data have high accuracy in the DNRP, the accuracy of the registration of time of the day is unknown. Inaccurate registration of time of admission may introduce bias in our estimates, but we assume such bias to be minor as the intervals range over many hours, thereby limiting the misclassification between two periods. In addition, time of admission is registered prospectively, independent of future events such as death or ICU admission.

Administrative databases provide extensive and valuable data, but variation in coding practices is an inherent limitation. ${ }^{26}$ Often, an acute condition associated with a chronic condition and the extent of diagnostic work up or complications during admission may influence coding practices. ${ }^{23}$ The accuracy of some diagnoses in the DNRP is known. For example, diagnosis of chronic obstructive pulmonary disorder, non-specific diagnosis of syncope, and diagnosis of acute stroke, have all been found to have reasonable high accuracy. ${ }^{27-29}$ Similarly, the accuracy of diagnostic coding for the conditions in the CCI has also been shown to be high. ${ }^{30}$ An ICU admission and the treatment provided during an ICU stay were identified with procedure codes, and these variables have high accuracy. ${ }^{31}$ Since we used a population-based registry to identify large groups of patients diagnosed, utilising the same ICD-10 codes, we assume that misclassification bias had only a minor impact, if any, on our results.

\section{Interpretation}

No previous studies have presented admission rates or changes in reasons for admission associated with time of admission. We found that hourly admission rates for the common conditions among acute medical patients vary between the different times of admission. This may be explained by differences in disease occurrence, and also by organisational differences, which changes the threshold for admission. This is supported by a higher mortality rate associated with admission outside office hours for the majority of the conditions examined. An example is anaemia, which demonstrated a tremendous decrease in admission rates outside weekday office hours. In patients with anaemia, the mortality rate and risk of an ICU admission more than doubled when patients were admitted during the weekend, which may infer an association with severity of the disease. In support of the hypothesis that more patients with severe illnesses are admitted during the weekend, previous studies on stroke, a common disorder that requires acute care, found that the 'weekend effect' disappeared after adjusting for deferred admissions and disease severity. ${ }^{32-34}$

Although the Danish healthcare system differs from the systems in other countries, our study lends support to previous evidence of a higher mortality associated with an acute admission during the weekend, and extends this by examining office hours versus out of hours, weekend daytime hours and weekend night-time hours. ${ }^{1-16}$ All earlier studies examined this effect by defining the weekend as starting on Friday at midnight and ending on Sunday at midnight. A few studies have examined mortality associated with admissions during out of hours, but no studies of an overall cohort of acute patients have distinguished between weekday out of hours and weekend daytime and night-time hours. ${ }^{8} 9$ The limited availability of the patients' personal GP and specialised care at the hospitals are assumed to apply to weekday out of hours, weekend hours and public holidays.

A few studies have examined the $24 \mathrm{~h}$ variation in admission. Despite the different reasons for admissions, the overall admission pattern forms a curve with two peaks, one during the mid-morning hours and one during the late afternoon hours. ${ }^{35-37}$ If this variation associates with a natural course of the diseases, a variation in prevalence and hence a variation in admission rates should be expected. However, this variation may more likely associate with the availability of the GPs.

A higher proportion of the patients arrived at the emergency department outside office hours. The reason for this could be associated with availability of GPs for consultation, or it could be patient related, associated with proportionally more patients with severe diseases presenting to departments of medicine outside office hours. A study from the UK, which examined the referral rates of acute hospital admission from GPs, found an increased referral rate outside office hours. ${ }^{38}$

Our study lacked clinical data on the severity of disease, but included information on the proportion of patients admitted to an ICU. We found a higher proportion of ICU admissions and organ supportive treatments during weekday out of hours and over the weekend compared with weekday office hours. Our findings contrasted with those from previous US and Australian studies. ${ }^{9}{ }^{39}$ The US study was based on medical record reviews of 824 admissions to general medicine units. The study found that weekend admissions were associated with a lower risk of ICU transfer. ${ }^{9}$ Differences in ICU settings between countries must be acknowledged when making comparisons of ICU admission rates. ${ }^{40}$

We considered an ICU admission and ICU procedures as proxies for severity of illness, although we also acknowledge the limitations in this approximation. 
For example, the use of ICU procedures is highly associated with age. ${ }^{41}$ Additionally, it is important to emphasise that some patients with severe illness will not be offered full therapy and that ICU admission also depends on bed availability. There are no national or European guidelines for admission and discharge from an ICU.

The present study may add important knowledge to healthcare planners about patient characteristics associated with admission outside office hours and the associated risk of ICU admission and death.

In conclusion, while admission rates decreased from office hours to weekend hours, there was an observed increase in mortality rates when comparing admission during weekend hours with admission during office hours. This may be explained by differences in severity of illness as measured by the need for ICU admission.

Contributors BV-H, AHR, HTS and CFC contributed to the study conception, design, and the acquisition and interpretation of data. BV-H analysed and drafted the manuscript. All authors critically revised the manuscript and approved the final version.

Funding The study was supported by the Clinical Epidemiological Research Foundation, Denmark and Aarhus University, Denmark.

Ethics approval The study was approved by the Danish Data Protection Agency (record number 1-16-02-1-08). Because the study was based solely on data from administrative and medical databases, no further approval from the Ethics Committee was required.

Competing interests None.

Provenance and peer review Not commissioned; externally peer reviewed.

Data sharing statement No additional data are available.

Open Access This is an Open Access article distributed in accordance with the Creative Commons Attribution Non Commercial (CC BY-NC 4.0) license, which permits others to distribute, remix, adapt, build upon this work noncommercially, and license their derivative works on different terms, provided the original work is properly cited and the use is non-commercial. See: http:// creativecommons.org/licenses/by-nc/4.0/

\section{REFERENCES}

1. Bell CM, Redelmeier DA. Mortality among patients admitted to hospitals on weekends as compared with weekdays. N Engl J Med 2001;345:663-8.

2. Cram $P$, Hillis SL, Barnett M, et al. Effects of weekend admission and hospital teaching status on in-hospital mortality. Am J Med 2004;117:151-7.

3. Schmulewitz L, Proudfoot A, Bell D. The impact of weekends on outcome for emergency patients. Clin Med 2005;5:621-5.

4. Barba R, Losa JE, Velasco M, et al. Mortality among adult patients admitted to the hospital on weekends. Eur J Intern Med 2006; 17:322-4.

5. Clarke MS, Wills RA, Bowman RV, et al. Exploratory study of the 'weekend effect' for acute medical admissions to public hospitals in Queensland, Australia. Intern Med J 2010;40:777-83.

6. Aylin P, Yunus A, Bottle A, et al. Weekend mortality for emergency admissions. A large, multicentre study. Qual Saf Health Care 2010;19:213-17.

7. Marco J, Barba R, Plaza S, et al. Analysis of the mortality of patients admitted to internal medicine wards over the weekend. Am J Med Qual 2010;25:312-18.

8. Maggs F, Mallet M. Mortality in out-of-hours emergency medical admissions-more than just a weekend effect. J $R$ Coll Physicians Edinb 2010;40:115-18.

9. Khanna R, Wachsberg K, Marouni A, et al. The association between night or weekend admission and hospitalization-relevant patient outcomes. J Hosp Med 2011;6:10-14.
10. Mikulich O, Callaly E, Bennett $\mathrm{K}$, et al. The increased mortality associated with a weekend emergency admission is due to increased illness severity and altered case-mix. Acute Med 2011;10:182-7.

11. Handel AE, Patel SV, Skingsley A, et al. Weekend admissions as an independent predictor of mortality: an analysis of Scottish hospital admissions. BMJ Open 2012;2:pii:e001789.

12. Smith S, Allan A, Greenlaw N, et al. Emergency medical admissions, deaths at weekends and the public holiday effect. Cohort study. Emerg Med J 2014;31:30-4.

13. Sharp AL, Choi H, Hayward RA. Don't get sick on the weekend: an evaluation of the weekend effect on mortality for patients visiting US EDs. Am J Emerg Med 2013;31:835-7.

14. Concha OP, Gallego B, Hillman K, et al. Do variations in hospital mortality patterns after weekend admission reflect reduced quality of care or different patient cohorts? A population-based study. BMJ Qual Saf 2014;23:215-22.

15. Madsen F, Ladelund S, Linneberg A. High levels of bed occupancy associated with increased inpatient and thirty-day hospital mortality in Denmark. Health Aff (Millwood) 2014;33:1236-44.

16. Mohammed MA, Sidhu KS, Rudge G, et al. Weekend admission to hospital has a higher risk of death in the elective setting than in the emergency setting: a retrospective database study of national health service hospitals in England. BMC Health Serv Res 2012;12:87.

17. Becker DJ. Weekend hospitalization and mortality: a critical review. Expert Rev Pharmacoecon Outcomes Res 2008;8:23-6.

18. Pedersen KM, Christiansen T, Bech M. The Danish health care system: evolution-not revolution-in a decentralized system. Health Econ 2005;14(Suppl 1):S41-57.

19. Andersen MS, Johnsen SP, Sorensen JN, et al. Implementing a nationwide criteria-based emergency medical dispatch system: a register-based follow-up study. Scand J Trauma Resusc Emerg Med 2013;21:53.

20. Wen LS, Anderson PD, Stagelund S, et al. National survey of emergency departments in Denmark. Eur J Emerg Med 2013;20:205-9.

21. Ministry of health and prevention. Health Care in Denmark. 2008. http://www.sum.dk/Aktuelt/Publikationer/ /media/Filer\%20-\% 20Publikationer_i_pdf/2008/UK_Healthcare_in_dk/pdf.ashx (accessed 28 Oct 2014).

22. Lynge E, Sandegaard JL, Rebolj M. The Danish national patient register. Scand J Public Health 2011;39(7 Suppl):30-3.

23. Vest-Hansen B, Riis AH, Sorensen HT, et al. Acute admissions to medical departments in Denmark: diagnoses and patient characteristics. Eur J Intern Med 2014;25:639-45.

24. Schmidt M, Pedersen L, Sorensen HT. The Danish Civil Registration System as a tool in epidemiology. Eur J Epidemiol 2014;29:541-9.

25. Kirkwood BR, Sterne JAC. Essential medical statistics. 2nd edn. Malden, MA: Blackwell Science, 2003:264-7.

26. Sorensen HT, Sabroe S, Olsen J. A framework for evaluation of secondary data sources for epidemiological research. Int $J$ Epidemiol 1996;25:435-42.

27. Thomsen RW, Lange $\mathrm{P}$, Hellquist $\mathrm{B}$, et al. Validity and underrecording of diagnosis of COPD in the Danish National Patient Registry. Respir Med 2011;105:1063-68.

28. Wildenschild C, Mehnert F, Thomsen RW, et al. Registration of acute stroke: validity in the Danish Stroke Registry and the Danish National Registry of Patients. Clin Epidemiol 2013;6:27-36.

29. Ruwald MH, Hansen ML, Lamberts M, et al. Accuracy of the ICD-10 discharge diagnosis for syncope. Europace 2013;15:595-600.

30. Thygesen SK, Christiansen CF, Christensen S, et al. The predictive value of ICD-10 diagnostic coding used to assess Charlson comorbidity index conditions in the population-based Danish National Registry of Patients. BMC Med Res Methodol 2011;11:83.

31. Blichert-Hansen L, Nielsson MS, Nielsen RB, et al. Validity of the coding for intensive care admission, mechanical ventilation, and acute dialysis in the Danish National Patient Registry: a short report. Clin Epidemiol 2013;5:9-12.

32. Turin TC, Kita Y, Rumana N, et al. Case fatality of stroke and day of the week: is the weekend effect an artifact? Takashima stroke registry, Japan (1988-2003). Cerebrovasc Dis 2008;26:606-11.

33. Jauss $\mathrm{M}$, Oertel W, Allendoerfer $\mathrm{J}$, et al. Bias in request for medical care and impact on outcome during office and non-office hours in stroke patients. Eur J Neurol 2009;16:1165-7.

34. Campbell JT, Bray BD, Hoffman AM, et al. The effect of out of hours presentation with acute stroke on processes of care and outcomes: analysis of data from the Stroke Improvement National Audit Programme (SINAP). PLoS One 2014;9:e87946.

35. McCarthy ML, Zeger SL, Ding R, et al. The challenge of predicting demand for emergency department services. Acad Emerg Med 2008;15:337-46. 
36. Kawakami C, Ohshige $\mathrm{K}$, Tochikubo O. Circadian variation in cardiovascular emergencies among the elderly. Clin Exp Hypertens 2008;30:23-31.

37. Dormann $\mathrm{H}$, Diesch K, Ganslandt $\mathrm{T}$, et al. Numerical parameters and quality indicators in a medical emergency department. Dtsch Arztebl Int 2010;107:261-7.

38. Rossdale M, Kemple T, Payne S, et al. An observational study of variation in GPs' out-of-hours emergency referrals. Br J Gen Pract 2007;57:152-4.
39. Asha SE, Titmuss K, Black D. No effect of time of day at presentation to the emergency department on the outcome of patients who are admitted to the intensive care unit. Emerg Med Australas 2011;23:33-8.

40. Wunsch $\mathrm{H}$, Angus DC, Harrison DA, et al. Variation in critical care services across North America and Western Europe. Crit Care Med 2008;36:2787-93, e1-9.

41. Nielsson MS, Christiansen CF, Johansen MB, et al. Mortality in elderly ICU patients: a cohort study. Acta Anaesthesiol Scand 2014;58:19-26. 